\title{
Voice Disorders and Prevalence in Opera Singers, Tirana
}

\author{
Dr. Zaharia Klodiana, Asoc. Prof. Shehi Agim
}

\begin{abstract}
:
Professional voice users often present to otolaryngologists with specific voice complaints. The contributions of pathologic lesions to the patients' vocal complaints are not always clear on examination, and often, premorbid routine examinations of the larynx are not available for review. Videolaryngostroboscopy is the examination that offer and preserve all the data useful by the doctor.

The aim of this study is to examine the prevalence and incidence of laryngeal pathology among classical professional singers, at the State Opera in Tirana, also to determine which handicaps are produced by a vocal problem and whether there are any relations to gender, age, vocal classification or total singing duration.
\end{abstract}

\section{Introduction}

Voice disorders, often known by the generic name dysphonia when caused by laryngeal pathology, convey the presence of a poor functioning of the voice in its most general aspects. The different types of dysphonia can be classified as: organic, functional and psychiatric. Voice professionals especially tend to present *nodular lesions, (fusiform edema, vocal cord nodules or serous pseudocysts); *hyperfunctional or hypofunctional dysphonia. All of these lesions are due to prolonged or inappropriate use of the voice.

Dysphonia is a pathological process that is very common among voice professionals and presents significant work-related, economic, social and cultural problems. However, the social significance of dysphonia in singers is not only related to sick leave, but also the fact that a dysphonic voice causes a feeling of insecurity, a lack of authority a change in personality and the isolation of the artist. The classical opera singing is a type of profane music and corresponds to the opera itself, which requires long training, dominance of vocal projection and vocal quality rich in harmonics. Such adjustments are of complex development and, if not well executed, may favor the development of vocal alterations and cause handicaps to the singer, with quality of life consequences.

Professional classical singers have demanding voice needs. Their voice is in a constant need of strength and high quality. They are also more exposed to the risk of developing voice problems.

\section{Method}

At the State Opera of Tirana, volunteers were recruited for a "free strobovideolaryngoscopic examination." All volunteers completed a specific de-tailed questionnaire of their vocal and medical history and the questionnaire of VHI. After completion of the questionnaire, a rigid strobovideolaryngoscopic examination was performed. All examinations were performed using the Kay Pentax $70^{\circ}$ rigid telescope and strobovideolaryngoscopic examinations were completed in 104 volunteers:

- 29 of whom had voice complaints and

- 75 of whom perceived their voices to be normal. 
Singers were asked to report whether they ever had a previously diagnosed voice problem and whether they had any vocal disability within the year prior to the study. Voice symptoms were studied. All of them undergo the program of Vocal Hygiene Habits, and the singers with symptoms undergo the resonant voice therapy for 6 weeks (3 times per week). After these procedures all the singers re-administrated the VHI questionnaire.

All participants were professional classical opera singers from the State Opera of Tirana, being 36 men and 68 women (mean age 32.82 years - being 23 the minimum and 65 the maximum age in years).

The participants were divided into six groups according to the vocal classification:

\section{- 50 sopranos,}

\section{- 14 mezzo-sopranos,}

- 2 contralto,

- 18 tenors,

\section{4 baritones}

\section{$\checkmark 6$ bass.}

The population was distributed into two groups according to presence or absence of vocal complaints:

29 choristers $(28 \%)$ had at least one vocal complaint and/or three or more vocal symptoms, while 75 choristers $(72 \%)$ had no complaints.

Participants were instructed to fill out the questionnaire and the protocol according to the instructions provided and to concentrate on their singing voice. The identification and characterization questionnaire contained data on vocal classification (according to the groups mentioned above), age, education, total dedication time to opera singing, voice quality, voice problems and presence of vocal symptoms (burning, itching, pain, dryness feeling, burning sensation, tightness or ball sensation, vocal fatigue and hoarseness). When the participant reported two or more symptoms, he or she was considered as presenting vocal complaints and, therefore, was assigned to the group with complaints. Age, educational level, and dedication time to singing were investigated by means of open questions.

We used the following inclusion criteria in the selection of cases of patients with pathology: all were professional singers, they reported having frequent symptoms of vocal hyperfunction (pharyngeal discomfort or neck tension, itching and hoarseness, changes in voice tone and pitch, voice interruptions while speaking, phonasthenia), they had a dysphonic voice and visible structural lesions on their vocal cords.

We followed the criteria of Bouchayer and Cornut (1994) in the laryngoscopic diagnosis of laryngeal pathologies and those of Hirano and Bless (1993) in the videostroboscopic examination of the larynx.

The study consisted of the following sections: a protocolized questionnaire (collecting the following data: personal and professional details, medical history, habits and vocal symptomology), endoscopic exam and videolaryngostroboscopy.

The prevalence or proportion of individuals from a population that had the illness at one particular moment and the incidence or number of new cases of an illness that develops in an at-risk population over a period of time were calculated .

The data obtained was entered into a database and processed with the program SPSS 11.0. Various statistical methods were applied depending on the type of variable analyzed: goodness-of-fit to a normal distribution (Kolmogorov-Smirnov), hypothesis contrast of two averages (Fisher-Student's $t$ test or Mann-Whitney's U test), lineal correlation analysis (Pearson's $r$ or Spearman's r).

\section{Results}

The prevalence of voice disorders among singers from State Opera in Tirana was 47\%: 24.8\% from organic lesions, [nodular lesions (11.8\%), polyps $(2 \%)$, submucous effusions (1.4\%), Reinke's edema $(1.1 \%)$, cysts $(0.5 \%)$, leucoplasia $(0.2 \%)$, vocal cord paralysis $(0.2 \%)], 4.1 \%$ from chronic laryngitis, gastroesophageal reflux (4.5\%)] and $22.2 \%$ from functional disorders [hyperfunctional dysphonia (5.5\%), hypofunctional dysphonia $(0.4 \%)$, vocal overexertion (14\%) and hyperplasia of the cords $(2.3 \%)$ ]. The incidence rate of voice disorders was 5 new cases per 1,000 singers per year. Organic lesions were more prevalent in women (19.4\%) than in men (5.4\%), but functional lesions and chronic laryngitis were more prevalent in men than in women.

Vocal fold masses were common among the asymptomatic professional singers. Evidence of reflux laryngitis was a common finding among both symptomatic and asymptomatic singers. Asymmetries in vocal fold hypomobility were more common among those with voice complaints than was the presence of vocal fold masses in the population studied. It was found that singers working more than 5 hours per day were 2.8 times more likely to have had a history of vocal disability in the year preceding the study. 
TABLE 1. Strobovideolaryngoscopy Findings in 104 Singers Volunteers

\begin{tabular}{lcccccc}
\multicolumn{1}{c}{$\begin{array}{c}\text { Vocal } \\
\text { Complaint }\end{array}$} & Complaint & \multicolumn{2}{c}{ No Vocal } & Total \\
Finding & $(\mathbf{n = 2 9 )}$ & $(\mathbf{\%})$ & $(\mathbf{n = 7 5 )}$ & $\mathbf{( \% )}$ & $\mathbf{( n = 1 0 4 )}$ & $\mathbf{( \% )}$ \\
\hline Reflux laryngitis & 29 & $(100)$ & 40 & $(53)$ & 69 & $(66)$ \\
Vocal fold cyst (unilateral or bilateral) & 12 & $(41)$ & 24 & $(32)$ & 36 & $(34)$ \\
Vocal fold polyp & 2 & $(6)$ & 4 & $(5)$ & 6 & $(5)$ \\
Varices & 5 & $(17)$ & 12 & $(16)$ & 17 & $(16)$ \\
Sulcus vocalis & 0 & $(0)$ & 16 & $(21)$ & 16 & $(15)$ \\
Reinke's edema & 3 & $(10)$ & 6 & $(8)$ & 9 & $(8)$ \\
Vocal fold scar & 0 & $(0)$ & 2 & $(2)$ & 2 & $(2)$ \\
Saccular cyst & 2 & $(6)$ & 4 & $(5)$ & 6 & $(5)$ \\
Vocal fold hypomobility & 18 & $(63)$ & 12 & $(16)$ & 30 & $(29)$
\end{tabular}

\section{Recomanditions}

These findings are congruent with the assumption that classical singers are more likely to experience and/or notice subtle voice changes and suffer dis- ability from them, which suggests that they should always consult the laryngologist and stay in close with phoniater also.

\section{References}

1. Santos LMA, Gasparini G, Behlau M. Validaзго do protocolo do Hndice de Desvantagem Vocal (IDV) no Brasil [monografia]. Sго Paulo: Centro de Estudos da Voz; 2007.

2. Rosen CA, Murry T. Voice Handicap Index in Singers. J Voice. 2000;14(3):370-7

3. Fussi F. La valutazione del canto. In: Fussi F. La voce del cantante. Torino: Omega Edizioni; 2005.v.3. p. 33-68 .

4. Cohen SM, Jacobson BH, Garrett CG, Noordzij JP, Stewart MG, Attia A et al. Creation and validation of the Singing Voice Handicap Index. Ann Oto Rhino Laryngol. 2007; 116(6): 402-6.

5. Cohen SM, Statham M, Rosen CA, Zullo T. Development and validation of the Singing Voice Handicap-10. Laryngoscope. 2009; 119(9): 1864-9.

6. World Health Organization. International classification of impairments, disabilities and handicaps: a manual of classification relating to the consequences of disease. Genebra: World Health Organization, 1980.

7. Jacobson B, Johnson A, Grywalsky C. The Voice Handicap Index (VHI): development and validation. Am J Speech Language Pathol. 1997; 6: 66-70.

8. Murry T, Zschommler A, Prokop J. Voice Handicap in singers. J Voice. 2009; 23(3): 376-9.

9. Moreti F, Rocha C, Borrego MCM, Behlau M. Desvantagem vocal no canto: anбlise do protocolo Hndice de Desvantagem para o Canto Moderno - IDCM. Rev Soc Bras Fonoaudiol. No prelo 2009.

10. Jotz GP, Bramati O, Schimidt VB, Dornelles S, Gigante LP. Aplicaзго do "Voice Handicap Index" em Coralistas. Arq Otorrinolaringol. 2002; 6(4): 260-64.

11. Cohen SM, Noordzij JP, Garrett CG, Ossoff RH. Factors associated with perception of singing voice handicap. Otolaryngol Head Neck Surg. 2008; 138(4): 430-4.

12. Miller MK, Verdolini K. Frequency and risk factors for voice problems in teachers of singing and control subjects. J Voice. 1995;9:348-362.

13. Phyland DJ, Oates J, Greenwood KM. Self-reported voice problems among three groups of professional singers. J Voice. 1999;13:602-611.

14. Elias ME, Sataloff RT, Rosen DC, Heuer RJ, Spiegel JR. Normal strobovideolaryngoscopy: variability in healthy singers. J Voice. 1997; 11: 104-107.

15. Lundy DS, Casiano RR, Sullivan PA, Roy S, Xue JW, Evans J. Incidence of abnormal laryngeal findings in asymptomatic singing students. Otolaryngol Head Neck Surg. 1999; 121: 69-77.

16. Sataloff. Professional voice: The Science and Art of Clinical Care. 2nd ed. San Diego, Calif: Singular Publishing Group, Inc., 1997.

17. Howard, D. M., \& Angus, J. A. S. (2001). Room acoustics. How they affect vocal production and perception. In P. H. Dejonkere (Ed.), Occupational voice - Care and Cure (pp. 29-46). The Hague, The Netherlands: Kugler.

18. Jonsdottir, V., Rantala, L., Laukkanen, A. M., \& Vilkman, E. (2001). Effects of sound amplification on teachers' speech while teaching. Logopedics, Phoniatrics, and Vocology, 26, 118-123.

19. Morton, V., \& Watson, D. R. (2001). The impact of impaired vocal quality on children's ability to process spoken language. Logopedics, Phoniatrics, and Vocology, 26, 17-25.

20. S. A. (1972). The foundations of factor analysis. New York: McGraw-Hill. 